\title{
Análise ambiental acerca da tutela dos recursos hídricos no Direito Ambiental brasileiro
}

\section{Vital José Pessoa Madruga Filho', Antônio Waldir Bezerra Cavalcanti Neto ${ }^{2}$, Paulo Joviniano Álvares dos Prazeres ${ }^{3}$}

\author{
${ }^{1}$ Universidade Federal da Paraíba. Centro de Ciências Exatas e da Natureza; \\ Programa de Pós-Graduação em Desenvolvimento e Meio Ambiente. Campus I. João \\ Pessoa-PB, Brasil (CEP 58051-900). E-mail: vitalpessoa@bol.com.br. \\ ${ }^{2}$ Tribunal de Justiça da Paraíba. Praça João Pessoa, S/№. Centro. João Pessoa-PB, \\ Brasil (CEP 58013-902). \\ ${ }^{3}$ Ordem dos Advogados do Brasil. Subseção Olinda. Avenida Presidente Kennedy, \\ 1.001. Peixinhos. Olinda-PE, Brasil (CEP 53230-630).
}

Resumo. 0 presente estudo perpassa pela análise relacional entre o meio ambiente e a vida na Terra, bem como os esforços empreendidos com o fito de resguardar as presentes e futuras gerações. Nesse sentir, é imperiosa a abordagem acerca da origem da vida no Planeta, como forma de compreender o surgimento do meio ambiente. Destarte, importa ressaltar os marcos jurídicos voltados à proteção ambiental, tanto em esfera nacional, como também no contexto internacional. A água é essencial à vida, e por isso recebe uma tutela jurídica especial, no patamar de direito fundamental, ocasião em que restou necessária a implantação de uma política voltada para o seu uso, disciplinada pela Lei $\mathrm{n}^{\mathrm{o}}$ 9.433/1997.

Palavras-chave: Água; Recursos hídricos; Direito Ambiental; Direito Fundamental.

\begin{abstract}
Environmental analysis on the protection of water resources in Brazilian Environmental Law. The present study is based on the relational analysis between the environment and life on Earth, as well as the efforts undertaken to protect present and future generations. In this sense, it is imperative to approach the origin of life on the Planet as a way of understanding the emergence of the environment. Therefore, it is important to highlight the legal frameworks for environmental protection, both at the national level and also in the international context. Water is essential to life, and therefore receives special legal protection, at the level of fundamental right, at which time it was necessary to implement a policy aimed at its use, governed by Law 9,433/1997.
\end{abstract}

Keywords: Water; Water resources; Environmental law; Fundamental Right.
Recebido: 06/08/2018

Aceito:

$27 / 08 / 2018$

Publicado: $31 / 08 / 2018$

Acesso aberto

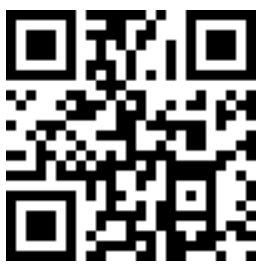

ORCID

(1) 0000-0002-0351-9807

Vital José Pessoa Madruga Filho

(ㄱ) 0000-0002-2834-9154

Antônio Waldir

Bezerra Cavalcanti Neto

(1) 0000-0002-5418-8155

Paulo Joviniano

Álvares dos Prazeres 


\section{Introdução}

A disponibilidade dos recursos hídricos no Planeta é uma das questões mais desafiadoras nos tempos hodiernos, em virtude da elevada e alarmante escassez deste recurso natural essencial à manutenção da vida na Terra.

Neste toar, a depreciação desse bem ambiental atrai efeitos nefastos ao ecossistema global, ocasionados ao crescimento econômico e ao uso irracional deste bem de uso comum de todos, conforme tratamento deferido pelo art. 225, da Constituição da República (Brasil, 1988).

Desde priscas eras, a concepção de água era abordada como recurso infinito, cujo entendimento começou a ser modificado a partir do século XX. Tanto é que o arcabouço legal que versa sobre os recursos hídricos, motivado pelas inúmeras crises que acometeram este recurso natural, advieram em contextos internacionais e nacionais, transformando a água em elemento econômico crucial para o século XXI, cuja escassez poderá atrairá conflitos bélicos, na mesma proporção em que o petróleo provocou estremecimentos e guerras desde o século anterior (Wolkmer e Pimennel, 2013). Os efeitos desta crise podem ser avaliados a partir dos níveis de degradação ambiental, provocados pelas inúmeras fontes de poluição, de sorte que a falta de água nos grandes centros urbanos e metrópoles, associadas às mudanças climáticas, é uma clara demonstração dos efeitos da ausência desse precioso bem natural.

A contextualização da história da água no presente estudo deve ser enlaçada com as mais importantes leis arraigadas ao tema, materializada na Lei no 9.433/1997 (Brasil, 1997), que instituiu a Política Nacional de Recursos Hídricos e criou o Sistema Nacional de Gerenciamento de Recursos Hídricos, alcunhada na seara jurídica como Lei das Águas.

O levantamento das teorias existentes sobre a origem da vida na
Terra, que se confundem com a própria formação do Planeta, e será encampada no trajeto que a água percorreu ao longo da história da humanidade, até ser aportada sob a tutela legal que lhe é reservada. Oportunamente, o surgimento do Direito Ambiental é matéria imprescindível para a caracterização dos grandes marcos internacionais, como é o caso da Conferência de Estocolmo, realizada em 1972, chegando até a edição da Encíclica Papal "Louvado Sejas", lançada em 2015, e subscrito pelo Papa Francisco (2015). A análise destes eventos denota a evidente preocupação da comunidade internacional para com o meio ambiente, de modo a suscitar na sociedade uma conversão de hábitos e atitudes ecológicas.

Assim, resta, pois, estudar a situação que a água exerce sobre o ordenamento jurídico pátrio, na medida em que se trata de recurso natural fundamental e essencial à sadia qualidade de vida na Terra.

\section{Surgimento da vida na Terra}

O surgimento da água é atrelado ao próprio surgimento da vida no Planeta, cujas explicações advém de diversas teorias atinentes ao assunto.

Cientistas sustentam que há aproximadamente 15 bilhões de anos, uma grande explosão ocorreu no Cosmos, em virtude de aglomerado altamente quente e denso e repleto de energia. A partir dessa explosão, uma grande quantidade de matéria e energia foi liberada, que resultou na formação do Universo (Silva et al., 2011).

Os resquícios e fragmentos decorrentes dessa grande explosão originou o Sol, que depois do decurso de 4 bilhões e 600 mil anos outros fragmentos passaram a contorná-lo, dando origem aos planetas. A partir de então, com o resfriamento gradual da crosta terrestre, obteve-se o surgimento dos mares e oceanos, de onde se brotou os primeiros seres vivos (Souza, 2009; Sampathkumaret al., 2010). 
Sob o prisma da Teoria Criacionista, corrente paralela ao que é preconizado pela Teoria Sintética da Evolução, tem-se na dicção do Antigo Testamento da Bíblia Cristã, a narrativa da criação do Universo:

No princípio criou Deus o céu e a terra. E a terra era sem forma e vazia; e havia trevas sobre a face do abismo; e o Espírito de Deus se movia sobre a face das águas. E disse Deus: Haja luz; e houve luz. E viu Deus que era boa a luz; e fez Deus a separação entre a luz e as trevas. E Deus chamou à luz de Dia; e às trevas chamou Noite. E foi a tarde e a manhã, o dia primeiro. E disse Deus: Haja uma expansão no meio das águas, e haja separação entre águas e águas. E fez Deus a expansão, e fez separação entre as águas que estavam debaixo da expansão e as águas que estavam sobre a expansão; e assim foi. E chamou Deus a expansão Céus, e foi a tarde e a manhã, o dia segundo. E disse Deus: Ajuntem-se as águas debaixo dos céus num lugar; e apareça a porção seca; e assim foi. E chamou Deus a porção seca Terra; e ao ajuntamento das águas chamou Mares; e viu Deus que era bom (Gn1, 1:10).

A Teoria Criacionista não é muito levada em conta pela comunidade científica, considerando a matriz mítica idealizada pelo autor do texto bíblico (Nicoliniet al., 2010), não obstante seja reconhecida que a "água é uma dádiva da Natureza e desempenha um papel fundamental no desenvolvimento de uma economia e, por sua vez, no bem-estar de uma nação" (Sampathkumar et al., 2010).

\section{Origem do Direito Ambiental}

O homem sempre verteu um olhar dominador e hegemônico junto ao meio em que está inserido, sem contanto calcular as consequências oriundas da sua intervenção na natureza, de modo que desde que começou a agrupar-se em clãs, vem se apoderando dos recursos naturais disponíveis, como meio de garantir e assegurar a sua própria subsistência.

Através de um olhar cronológico, percebe-se que os homens se organizavam em sociedade a partir das margens de rios, lagos e mares, de forma que os recursos hídricos, fundamentais à manutenção da vida, eram explorados pelas populações locais ali estabelecidas. Assim aconteceu com os egípcios, através das terras férteis assistidas pelo Rio Nilo; com os fenícios, que se estabeleceram nas encostas dos mares e dele tiraram proveito comercial e de subsistência; bem como com os gregos e romanos. Já na Idade Média, as águas tomaram uma função muito mais elevada do que a própria manutenção da vida, mas assumiram a função de transportes, exercendo função econômica de grande valia para aquela população medieval que trilhava os caminhos da expansão territorial (Souza, 2009).

No século XIX, a partir do grande marco capitalista fundado pela Revolução Industrial, as sociedades sofreram profundas transformações econômicas, sociais, políticas e etc., voltadas à exploração desenfreada dos recursos naturais, cujas consequências foram sentidas pela população global, que passou a reclamar por preservação ambiental (Souza, 2009), chegando ao ponto de Malthus (1798), pela primeira vez, chamar a atenção para o crescimento populacional descontrolado e a escassez dos alimentos.

Com a eclosão da Segunda Grande Guerra, nasceu o interesse de conciliar a ação humana à valorização e preservação do meio ambiente, capaz de garantir sustentabilidade para as presentes e futuras gerações, de modo que restou patente que os valores políticos e econômicos exercem influência direta no desenvolvimento do processo de degradação ambiental, bem como na tomada de consciência acerca da necessidade de preservação da natureza e dos recursos naturais (Vieira e Ribeiro, 2010). Deste modo, na década de 1960 a 
visibilidade dos danos já podiam ser denotados a olhos vistos, considerando a gama de desastres e desequilíbrios ambientais que asseveraram-se ao longo dos anos em todo o Planeta (Medeiros, 2014).

\section{Conferência de Estocolmo}

Em 1972, as Nações Unidas, despertou pela primeira vez a necessidade de se reservar ao meio ambiente tratamento protecionista em favor da sistematização de ferramentas voltadas à tutela do Meio Ambiente, através da Conferência de Estocolmo (Paz, 2010). A partir de então, restou evidente que a ação do homem na natureza possuía o condão de variável ambiental, de modo que com a edição da Declaração Universal do Meio Ambiente, as questões ambientais foram direcionadas como tema de preocupação próprio da comunidade internacional, inaugurando o que se entende por ecopolítica ambiental (Dutra, 2010).

Para Passos (2009), o modelo econômico adotado a partir da Revolução Industrial levava o homem a exercer hegemonia e domínio sobre a natureza, o que desencadeou um vertiginoso processo de exploração desmedida dos recursos naturais, culminando com os grandes problemas naturais testemunhados em todo o mundo.

De acordo com Le Preste (2005) e Passos (2009), a Conferência de Estocolmo foi capaz de sensibilizar os Estados acerca da existência de questões pertinentes à mudanças climáticas $\mathrm{e}$ grande crise hídrica que afetou e vem afetando a qualidade e a quantidade das águas postas em disponibilidade para consumo humano. Nesse contexto, foi possível depurar enorme avanço de campanhas publicitárias, com o fito de chamar a atenção da comunidade internacional, sobre os problemas ambientais, levando-se a cabo a ocorrência de desastres naturais, os problemas da explosão demográfica, principalmente em virtude do êxodo rural, e assim, orientá-la a uma possível tomada de consciência.

É preciso ter em mente que a partir desta manifesta preocupação ambiental, estabelecida na Conferência de Estocolmo de 1972, elencaram-se princípios e fundamentos básicos propícios à formação do Direito Ambiental, tendente à mantença do melhoramento e aprimoramento do Planeta em produzir recursos renováveis. Neste prisma, os tratados estabelecidos nos idos de 1972, levam à consideração de que o direito ao meio ambiente ecologicamente equilibrado, é um verdadeiro direito humano, que deve orientar os paradigmas afetos ao desenvolvimento sustentável, à luta em combate à poluição, à proteção da biodiversidade, os valores da Justiça Social, a cooperação e adequação dos fatores relacionados à solução das questões e contendas ambientais (Grazinera, 2014).

\section{Encíclica papal “Louvado Sejas”}

Nos dias atuais, os problemas ambientais e, consequentemente, as crises econômicas, políticas e sociais que deles decorrem, mostra-se como elemento preocupante e atual, que foi capaz de despertar no Papa Francisco, a necessidade de manifestar-se, em 2015, sua atenção para com o meio ambiente, através da publicação da Encíclica: "Louvado Sejas", sobre o cuidado da casa comum; Percebe-se que o documento foi redigido em seis capítulos, e atem-se às mudanças climáticas, a dívida ecológica, o problema dos recursos hídricos, a crise ecológica e as mudanças atinentes ao estilo de vida das pessoas, na esperança de chamar a atenção das instituições que lhe são coligadas e dos fieis que o seguem na Fé, acerca da importância do trata para com a natureza na proteção da vida na Terra.

No que diz respeito à crise hídrica, Papa Francisco (2015) enaltece que o acesso à água potável deve ser considerada como direito humano 
fundamental e universal, que condiciona à sobrevivência do homem, de modo que negar acesso à água é o mesmo que negar a vida. Dada esta questão, Lanfred (2006) e Passos (2009) destacam que a escassez de água potável poderá dar origem a conflitos e disputas entre estados.

Ainda sobre essa celeuma, o Romano Pontífice (Papa Francisco, 2015) salienta acerca dos movimentos dos grandes grupos econômicos no sentido de buscar a privatização do recurso escasso, o que caracterizaria a água como objeto de mercado e das leis que o regem, considerando que estudos apontam que daqui a algumas décadas, a humanidade poderá sofrer uma nefasta crise em decorrência da escassez dos recursos hídricos.

\section{Direito Ambiental brasileiro}

0 Direito Ambiental possui jovialidade cronológica no ordenamento jurídico pátrio, o que não ilide sua importância e imprescindibilidade na normatização de questões tão nobres e importantes para a vida das pessoas. Desse modo, alguns doutrinadores sustentam que a Lei no 6.938/1981, que dispõe sobre a Política Nacional do Meio Ambiente, foi quem inaugurou $o$ ambientalismo na seara jurídica do Brasil (Brasil, 1981).

0 art. 3o, da Lei no 6.938/1981, traz a conceituação legal de meio ambiente, considerando-o como "[...] o conjunto de condições, leis, influências e interações de ordem física, química e biológica, que permite, abriga e rege a vida em todas as suas formas" (Brasil, 1981).

Nesta senda, as questões ambientais devem ser deparadas sob uma visão holística, de sorte que o art. 225, da Constituição da Federal de 1988, dedica-se ao meio ambiente, ao estabelecer que:

Todos têm direito ao meio ambiente ecologicamente equilibrado, bem de uso comum do povo e essencial à sadia qualidade de vida, impondo-se ao Poder Público e à coletividade o dever de defendê-lo e preservá-lo para as presentes e futuras gerações (Brasil, 1988).

De forma analítica, a Constituição Federal, além de recepcionar a temática ambiental, ainda deferiu-lhe sentido mais amplo ao que ficou estabelecido na Lei $\mathrm{n}$ 6.938/1981 (Brasil, 1981).

0 texto constitucional valeu-se de diversas técnicas legiferantes em prol da tutela do meio ambiente, levando como fundamentos os direitos e deveres fundamentais, princípios, objetivos públicos vinculantes, instrumentos, função ecológica da propriedade e áreas especialmente protegidas (Siqueira, 2008).

Perceptivelmente, fica claro e evidente que o legislador constitucional buscou conciliar à vida humana e o meio ambiente em que ele está inserido, com vistas à uma integração harmônica e pacífica.

Dessa forma, considerando a essencialidade da água, faz-se imperioso destacar sua importância para a manutenção da vida na Terra sob a ótica de bem jurídica tutelado.

\section{Lei das Águas (Lei no 9.433/1997)}

Um dos aspectos mais importantes acerca da Lei das Águas (Lei no 9.433/1997) foi a instituição da Política Nacional de Recursos Hídricos (PNRH), fundamentando o seu mister nos seguintes fundamentos (Brasil, 1997):

Art. 1ํ A Política Nacional de Recursos Hídricos baseia-se nos seguintes fundamentos:

I - a água é um bem de domínio público;

II - a água é um recurso natural limitado, dotado de valor econômico; III - em situações de escassez, o uso prioritário dos recursos hídricos é o 
consumo humano e a dessedentação de animais;

IV - a gestão dos recursos hídricos deve sempre proporcionar o uso múltiplo das águas;

V - a bacia hidrográfica é a unidade territorial para implementação da Política Nacional de Recursos Hídricos e atuação do Sistema Nacional de Gerenciamento de Recursos Hídricos;

VI - a gestão dos recursos hídricos deve ser descentralizada e contar com a participação do Poder Público, dos usuários e das comunidades.

Deste modo, a natureza pública das águas constitui o primeiro fundamento da PNRH, cujo bem é dotado de inalienabilidade no ordenamento jurídico pátrio, o que o torna na condição de bem de uso comum do povo.

Assim, refuta-se a ideia de particularização das águas, pois de acordo com preceituação emoldurada pela Constituição da República (art. 20, incisos III, IV e VIII, c/c art. 26, inciso I) as águas são constituídas na qualidade de bens da União, quando não lhe pertencerem, serão consideradas bens dos Estados. Gize-se que a titularidade municipal não foi encampada pelo Texto Maior.

A motivação desse critério de publicização das águas, decorre da latente crise hídrica que assola o Brasil e o mundo, em razão da escassez de água doce, impingida pelos alarmantes níveis de desperdício e da poluição dos mananciais e reservas hídricas. Por essa razão, a fim de evitar exploração de capital por parte de grupos econômicos, que seguramente tornaria a população vulnerável aos desmandos capitalistas desses grupos. Portanto, incumbe ao Poder Público, o dever de proteção e gerenciamento dos recursos hídricos, como forma de preservar o interesse coletivo e manter uma boa qualidade deste recurso natural (Amado, 2017).

Deste modo, sabe-se que o entendimento predominante sobre a água é que se trata de um recurso renovável, em razão do ciclo hidrológico, mas que é limitado, permeado por um custo ambiental derivado do seu uso e consumo, cuja cobrança pecuniária tem o condão de promover uma racionalização do seu consumo, salvo a população carente, que não poderá ser privada da utilização desse bem vital à manutenção da vida (Amado, 2017).

Nesse sentido, o STJ manifestouse no seguinte julgado, in verbis:

ADMINISTRATIVO.
DESAPROPRIAÇÃO. INDENIZAÇÃO.
OBRA REALIZADA POR TERCEIRA
PESSOA EM ÁREA DESAPROPRIADA.
BENFEITORIA. NÃO CARACTERIZA-
ÇÃO. PROPRIEDADE. SOLO E
SUBSOLO. DISTINÇÃO. ÁGUAS
SUBTERRÂNEAS. TITULARIDADE.
EVOLUÇÃO LEGISLATIVA. BEM
PÚBLICO DE USO COMUM DE
TITULARIDADE DOS ESTADOS-
MEMBROS. CÓDIGO DE ÁGUAS. LEI
No 9.433/97. CONSTITUIÇÃO
FEDERAL, ARTS. 176, 176 E 26, I. 1.

Benfeitorias são as obras ou despesas realizadas no bem, para o fim de conservá-lo, melhorá-lo ou embelezá-lo, engendradas, necessariamente, pelo proprietário ou legítimo possuidor, não se caracterizando como tal a interferência alheia.

2. A propriedade do solo não se confunde com a do subsolo (art. 526, do Código Civil de 1916), motivo pelo qual $o$ fato de serem encontradas jazidas ou recursos hídricos em propriedade particular não torna o proprietário titular do domínio de referidos recursos (arts. 176, da Constituição Federal).

3. Somente os bens públicos dominiais são passíveis de alienação e, portanto, de desapropriação.

4. A água é bem público de uso comum (art. 1o da Lei no 9.433/97), motivo pelo qual é insuscetível de apropriação pelo particular.

5. 0 particular tem, apenas, o direito à exploração das águas subterrâneas mediante autorização do Poder Público cobrada a devida 
contraprestação (arts. 12, II e 20, da Lei $\mathrm{n}^{\mathrm{o}}$ 9.433/97).

6. Ausente a autorização para exploração a que o alude o art. 12, da Lei $\mathrm{n}$ - 9.443/97, atentando-se para o princípio da justa indenização, revela-se ausente $o$ direito à indenização pelo desapossamento de aqüífero.

7. A ratio deste entendimento devese ao fato de a indenização por desapropriação estar condicionada à inutilidade ou aos prejuízos causados ao bem expropriado, por isso que, em não tendo o proprietário o direito de exploração de lavra ou dos recursos hídricos, afasta-se o direito à indenização respectiva.

8. Recurso especial provido para afastar da condenação imposta ao INCRA o quantum indenizatório fixado a título de benfeitoria.

(STJ - REsp: 518744 RN 2003/0048439-9, Relator: Ministro LUIZ FUX, Data de Julgamento: 03/02/2004, T1 - PRIMEIRA TURMA, Data de Publicação: --> DJ 25/02/2004 p. 108RT vol. 825 p. 200)

As águas possuem múltiplas utilidades para a vida, servindo de base para consumo humano, para satisfazer recreações, necessidades dos animais, da indústria, da agricultura, sendo importante meio para navegação e geração de energia e etc. No entanto, em momentos de crise hídrica, ocasionadas especificamente pela escassez, deve-se tomar à cabo algumas prioridades avençadas pela própria legislação (art. 7ํ, inciso VIII, da Lei no 9.433/1997), evitando uma gastança geral deste recurso que, como dito antes, é limitado por força natural.

Com efeito, a legislação deferiu proteção mais acurada às bacias hidrográficas, em razão destas servirem de drenagem para o curso natural das águas, de modo que sua unidade territorial definirá a pauta de atuação das entidades responsáveis pela consecução do PNRH.
Diante da necessidade evidente e necessária de se garantir maior proteção e defesa às bacias hidrográficas, o novíssimo Código Florestal (art. 61-A, § 17, da Lei no 12.651/2012) atribuiu ao chefe do Poder Executivo, a incumbência de tomar a responsabilidade pela recuperação das áreas degradadas em adjacência às bacias, com vistas a conservação da vegetação nativa e ciliar, em nível prioritário na esfera de governo (Brasil, 2012).

Com o intuito da completa implementação dos objetivos descritos na Política Nacional de Recursos Hídricos (PNRH), foram propostos seis instrumentos, os quais deverão ser implementados pela União e pelos entes federativos, os planos de recursos hídricos, o enquadramento dos corpos de água, a outorga dos direitos de uso, a cobrança pelo uso de recursos hídricos, a compensação aos municípios e o sistema de informações (Peres e Silva, 2013)

Importa salientar que a gestão dos recursos hídricos deve ocorrer de forma descentralizada, conforme fundamento insculpido no próprio PNRH, que contará com uma intervenção tripartite, composta de representante do Poder Público, das comunidades e dos usuários, como forma de garantir maior participatividade e intervenção popular no processo de tomada de decisão, como forma de valorizar e promover o empoderamento popular.

A fim de viabilizar a concretude da norma, a Lei no 9.433/1997 prevê no rol do art. 5o os instrumentos hábeis que dispõe a Política Nacional de Recursos Hídricos, cujo destaque deve-se conferir a outorga e cobrança pelo uso da água. Além do mais, com fito de assegurar acesso à informação, e como forma de propiciar maior controle da sociedade acerca dos recursos hídricos disponíveis no País, o art. 5oㅡ, inciso VI, prevê a criação do Sistema de Informações sobre Recursos Hídricos, que possui a finalidade de reunir dados sobre a qualidade e a quantidade da água no Brasil. 
Outra preocupação bastante pertinente, diz respeito à viabilidade do abastecimento de água frente a uma população que cresce demograficamente cada vez mais, de modo que eventual ocupação e uso irregular do solo e de insumos agroindustriais poderão carrear graves impactos ambientais, podendo agravar o quadro de escassez de água potável.

\section{Água na condição de direito fundamental}

Com a gradativa deferência reservada ao meio ambiente em todo mundo, a partir da Conferência de Estocolmo de 1972 até a edição da Encíclica Papal de 2015, tem-se que o contexto evolutivo da noção de meio ambiente o eleva ao patamar de um direito fundamental, tutelado em proveito do equilíbrio ecológico das relações sociais, políticas e econômicas.

Indubitavelmente, sabe-se que a água exerce posição privilegiada quando o assunto é a manutenção da vida no Planeta. Desta forma, este recurso natural vem ganhando espaços cada vez mais consolidados nos tratados internacionais, bem como no ordenamento jurídico brasileiro, na medida em que se trata de um elemento cada vez mais ameaçado de escassez por toda a Terra.

Além do mais, é sabido que a água é elemento imprescindível para o fomento de atividades ligadas ao processo de desenvolvimento socioeconômico, considerando que sua utilidade atinge diversos patamares (Souza, 2015). De acordo com dados levantados por Giehl (2015), grande porção da água encontrada no Planeta não é potável. Segundo o estudioso, 70\% da superfície do hemisfério global está tomada por água, sendo que $97 \%$ dessa matéria prima é salgada e apenas $3 \%$ é composta de água doce, da qual apenas 0,01\% está disponível para consumo uso, haja vista que o restante está situado em icebergs, geleiras e em camadas de subsolo demasiadamente profundas.

$\mathrm{Na}$ forma do art. 225, da Constituição da República (Brasil, 1988), cumpre ao estado legislar sobre temas que privilegiem a tutela da água, na condição de Direito Fundamental que esta matéria-prima exerce no contexto jurídico brasileiro, devendo viabilizar a materialização desse direito no meio social, bem como elencar políticas públicas voltadas para o uso racional e consciente dos recursos hídricos (Rangel, 2014).

Destarte, com a edição do Código de Defesa e Proteção do Consumidor (Lei no 8.078/1990), o art. 81 visa a instrumentalizar a tutela dos direitos e interesses difusos, admitindo, pois, a utilização de mecanismos jurídicos hábeis à defesa dos interesses coletivos, veja-se:

Art. 81. A defesa dos interesses e direitos dos consumidores e das vítimas poderá ser exercida em juízo individualmente, ou a título coletivo.

Parágrafo único. A defesa coletiva será exercida quando se tratar de:

I - interesses ou direitos difusos, assim entendidos, para efeitos deste código, os transindividuais, de natureza indivisível, de que sejam titulares pessoas indeterminadas e ligadas por circunstâncias de fato; [...] (Brasil, 1990).

É característica do direito difuso a sua indivisibilidade, tendo em vista que sua utilização é oponível em favor de toda a coletividade, sendo pertença de todos, de modo que nenhum indivíduo, de forma pessoal, o detém na condição de direito subjetivo (Fiorillo, 2008). Todavia, seu domínio e uso é de competência do Estado, sendo um mister de toda a coletividade seu acesso, assim como ocorre, de forma paritária, o meio ambiente.

Acerca da matéria, é de se colher importante julgado do Supremo Tribunal 
Federal, quando do julgamento da ADI 3.540 , sob a relatoria do Min. Celso de Mello, DJ de 03/02/2006, veja-se:

MEIO AMBIENTE - DIREITO À PRESERVAÇ̃̃O DE SUA INTEGRIDADE (CF, ART. 225) - PRERROGATIVA QUALIFICADA POR SEU CARÁTER DE METAINDIVIDUALIDADE DIREITO DE TERCEIRA GERAÇÃO (OU DE NOVÍSSIMA DIMENSÃO) QUE CONSAGRA O POSTULADO DA SOLIDARIEDADE - NECESSIDADE DE IMPEDIR QUE A TRANSGRESSÃO A ESSE DIREITO FAÇA IRROMPER, NO SEIO DA COLETIVIDADE, CONFLITOS INTERGENERACIONAIS - ESPAÇOS TERRITORIAIS ESPECIALMENTE PROTEGIDOS (CF, ART. 225, § 1으, III) - ALTERAC̃̃̃O E SUPRESSÃO DO REGIME JURÍDICO A ELES PERTINENTE - MEDIDAS SUJEITAS AO PRINCÍPIO CONSTITUCIONAL DA RESERVA DE LEI - SUPRESSÃO DE VEGETAÇ̃̃O EM ÁREA DE PRESERVAÇ̃̃O PERMANENTE - POSSIBILIDADE DE A ADMINISTRAÇÃO PÚBLICA, CUMPRIDAS AS EXIGÊNCIAS LEGAIS, AUTORIZAR, LICENCIAR OU PERMITIR OBRAS E/OU ATIVIDADES NOS ESPAÇOS TERRITORIAIS PROTEGIDOS, DESDE QUE RESPEITADA, QUANTO A ESTES, A INTEGRIDADE DOS ATRIBUTOS JUSTIFICADORES DO REGIME DE PROTEÇÃO ESPECIAL RELAÇÕES ENTRE ECONOMIA (CF, ART. 3으, II, C/C O ART. 170, VI) E ECOLOGIA (CF, ART. 225) - COLISÃO DE DIREITOS FUNDAMENTAIS CRITÉRIOS DE SUPERAÇ̃̃O DESSE ESTADO DE TENSÃO ENTRE VALORES CONSTITUCIONAIS RELEVANTES - OS DIREITOS BÁSICOS DA PESSOA HUMANA E AS SUCESSIVAS GERAÇÕES (FASES OU DIMENSÕES) DE DIREITOS (RT) 164/158, 160161) - A QUESTÃO DA PRECEDÊNCIA DO DIREITO À PRESERVAÇÃO DO MEIO AMBIENTE: UMA LIMITACÃO CONSTITUCIONAL EXPLÍCITA À ATIVIDADE ECONÔMICA (CF, ART. 170, VI) - DECISÃO NÃO REFERENDADA - CONSEQÜENTE INDEFERIMENTO DO PEDIDO DE MEDIDA CAUTELAR. A PRESER-
VAÇÃO DA INTEGRIDADE DO MEIO AMBIENTE: EXPRESSÃO CONSTITUCIONAL DE UM DIREITO FUNDAMENTAL QUE ASSISTE À GENERALIDADE DAS PESSOAS.

Todos têm direito ao meio ambiente ecologicamente equilibrado. Trata-se de um típico direito de terceira geração (ou de novíssima dimensão), que assiste a todo o gênero humano (RTJ 158/205-206). Incumbe, ao Estado e à própria coletividade, a especial obrigação de defender e preservar, em benefício das presentes e futuras gerações, esse direito de titularidade coletiva e de caráter transindividual (RT) 164/158-161). 0 adimplemento desse encargo, que é irrenunciável, representa a garantia de que não se instaurarão, no seio da coletividade, os graves conflitos intergeneracionais marcados pelo desrespeito ao dever de solidariedade, que a todos se impõe, na proteção desse bem essencial de uso comum das pessoas em geral. Doutrina. A ATIVIDADE ECONÔMICA NÃO PODE SER EXERCIDA EM DESARMONIA COM OS PRINCÍPIOS DESTINADOS A TORNAR EFETIVA A PROTEÇÃO AO MEIO AMBIENTE. - A incolumidade do meio ambiente não pode ser comprometida por interesses empresariais nem ficar dependente de motivações de índole meramente econômica, ainda mais se se tiver presente que a atividade econômica, considerada a disciplina constitucional que a rege, está subordinada, dentre outros princípios gerais, àquele que privilegia a "defesa do meio ambiente" (CF, art. $170, \mathrm{VI}$ ), que traduz conceito amplo e abrangente das noções de meio ambiente natural, de meio ambiente cultural, de meio ambiente artificial (espaço urbano) e de meio ambiente laboral. Doutrina. Os instrumentos jurídicos de caráter legal e de natureza constitucional objetivam viabilizar a tutela efetiva do meio ambiente, para que não se alterem as propriedades e os atributos que lhe são inerentes, o que provocaria inaceitável comprometimento da 
saúde, segurança, cultura, trabalho e bem-estar da população, além de causar graves danos ecológicos ao patrimônio ambiental, considerado este em seu aspecto físico ou natural. A QUESTÃO DO DESENVOLVIMENTO NACIONAL (CF, ART. 3으, II) E A NECESSIDADE DE PRESERVAÇÃO DA INTEGRIDADE DO MEIO AMBIENTE (CF, ART. 225): O PRINCÍPIO DO DESENVOLVIMENTO SUSTENTÁVEL COMO FATOR DE OBTENÇÃO DO JUSTO EQUILÍBRIO ENTRE AS EXIGÊNCIAS DA ECONOMIA E AS DA ECOLOGIA. - 0 princípio do desenvolvimento sustentável, além de impregnado de caráter eminentemente constitucional, encontra suporte legitimador em compromissos internacionais assumidos pelo Estado brasileiro e representa fator de obtenção do justo equilíbrio entre as exigências da economia e as da ecologia, subordinada, no entanto, a invocação desse postulado, quando ocorrente situação de conflito entre valores constitucionais relevantes, a uma condição inafastável, cuja observância não comprometa nem esvazie o conteúdo essencial de um dos mais significativos direitos fundamentais: o direito à preservação do meio ambiente, que traduz bem de uso comum da generalidade das pessoas, a ser resguardado em favor das presentes e futuras gerações. O ART. 4ํ DO CÓDIGO FLORESTAL E A MEDIDA PROVISÓRIA № 2.166-67/2001: UM AVANÇO EXPRESSIVO NA TUTELA DAS ÁREAS DE PRESERVAÇÃO PERMANENTE.- A Medida Provisória no 2.166-67, de 24/08/2001, na parte em que introduziu significativas alterações no art. $4^{\circ}$ do Código Florestal, longe de comprometer os valores constitucionais consagrados no art. 225 da Lei Fundamental, estabeleceu, ao contrário, mecanismos que permitem um real controle, pelo Estado, das atividades desenvolvidas no âmbito das áreas de preservação permanente, em ordem a impedir ações predatórias e lesivas ao patrimônio ambiental, cuja situação de maior vulnerabilidade reclama proteção mais intensa, agora propiciada, de modo adequado e compatível com o texto constitucional, pelo diploma normativo em questão. - Somente a alteração e a supressão do regime jurídico pertinente aos espaços territoriais especialmente protegidos qualificam-se, por efeito da cláusula inscrita no art. 225, § 1ํㅡ. III, da Constituição, como matérias sujeitas ao princípio da reserva legal. - É lícito ao Poder Público - qualquer que seja a dimensão institucional em que se posicione na estrutura federativa (União, Estados-membros, Distrito Federal e Municípios) - autorizar, licenciar ou permitir a execução de obras e/ou a realização de serviços no âmbito dos espaços territoriais especialmente protegidos, desde que, além de observadas as restrições, limitações e exigências abstratamente estabelecidas em lei, não resulte comprometida a integridade dos atributos que justificaram, quanto a tais territórios, a instituição de regime jurídico de proteção especial (CF, art. 225, $\S 1^{\circ}$, III) (Brasil, 2006).

O entendimento firmado pelo Pleno do Supremo Tribunal Federal, corrobora com o fundamento jurídico que capitula o meio ambiente à condição de Direito Fundamental, que deve assistir à generalidade dos indivíduos, na forma prescrita no art. 225, da CF/1988.

$\mathrm{Na}$ condição de direito fundamental de terceira geração, que prima pela solidariedade, o direito ao acesso à água é irrenunciável, cabendo ao Estado o cumprimento de tal desiderato, como forma de prevenir graves conflitos intergeracionais, oriundos do aviltamento ao dever de solidariedade imposta a todos, com vistas à proteção dos recursos hídricos.

É cediço que a atividade econômica muitas vezes hostiliza as questões ambientais e provocam profunda degradação aos recursos naturais e a natureza como um todo. Dessa forma, consoante dicção do art. 170, inciso VI, da CF/1988, a atividade econômica deve perfilhar-se ao princípio da "defesa do meio ambiente" (Brasil, 1988). Desse modo, há verdadeira tutela 
constitucional na esperança de se resguardar a inalterabilidade das propriedades e os atributos arraigados ao meio ambiente, caso contrário, estabelecer-se-ia verdadeiro caos na saúde, segurança, cultura, bem-estar e trabalho da sociedade, além dos nefastos impactos ecológicos direcionados ao patrimônio ambiental, em sua dimensão física e natural.

Neste cenário, exsurge os ditames inerentes ao desenvolvimento sustentável, quando se restringe a máxime da atividade econômica em proveito da incolumidade ambiental, como forma de se obter o equilíbrio e a conjugação dos fatores econômicos, ecológicos e sociais.

\section{Considerações Finais}

Diante da importância e alocação histórica da água, através das dimensões físicas, culturais e religiosas, tem-se que o acesso a esse recurso natural é condição de subsistência para os seres vivos do Planeta, de modo que a partir das mudanças políticas, econômicas e sociais vivenciadas pela sociedade foi imprescindível o advento de um regramento jurídico voltado para a correta utilização do meio ambiente e dos recursos naturais dele provenientes.

Neste contexto, a partir do final do século XIX e na segunda metade do século XX, surge o Direito Ambiental, atraído por uma concepção holística dos problemas ambientais e como forma de frear os avanços desmedidos e inconsequentes gerados pelo mercado de produção e consumo.

A Conferência de Estocolmo, os diversos fóruns que serviram de palco para discussão dos problemas ambientais e a Encíclica Papal foram capazes de abordar a temática socioambiental no mundo e em todos os setores da sociedade civil organizada, pontuando a preocupação universal acerca de se assegurar um meio ambiente ecologicamente equilibrado, capaz de garantir a manutenção da vida no Planeta.

$\mathrm{Na}$ condição de direito difuso, oponível à todos de forma genérica e indistinta, o Poder Público, na condição de legítimo representante dos interesses da população, deve assegurar o acesso à água, como condição imprescindível de favorecer o exercício do direito à vida.

Portanto, a água se apresenta como recurso ambiental de domínio público, dotado de valor econômico, finito e que atinge gerações vindouras, de sorte que a proteção e a utilização de ferramentas voltadas para a tutela dos recursos hídricos é condição de sobrevivência e mantença da vida em suas diversas espécies no Planeta.

\section{Conflito de interesses}

Os autores declaram não haver conflito de interesses.

\section{Referências}

Amado, F. Direito Ambiental. 5. ed. São Paulo: Juspodivm, 2017.

Bíblia Sagrada. Tradução dos Monges Beneditinos e Maredsous. Gêneses. 79. Ed. São Paulo: Ave-Maria, 2009. Cap. 1, p. 49.

Brasil. Constituição da República Federativa do Brasil de 1988. Disponível em: <http://www.planalto.gov.br/ccivil_03/ constituicao/ConstituicaoCompilado.htm>.

Acesso em: 23 jul. 2018.

Brasil. Decreto no 24.643, de 10 de julho de 1934. Decreta o Código de Águas. Disponível em: <http://www.planalto. gov.br/ccivil_03/decreto/d24643.htm>.

Acesso em: 23 jul. 2018.

Brasil. Lei no 6.938, de 31 de agosto de 1981. Dispõe sobre a Política Nacional do Meio Ambiente, seus fins e mecanismos de formulação e aplicação, e dá outras providências. Disponível em: <http://www.planalto.gov.br/ccivil_03/leis/ L6938.htm>. Acesso em: 23 jul. 2018.

Brasil. Lei no 8.078, de 11 de setembro de 1990. Dispõe sobre a proteção do consumidor e dá outras providências. Disponível em: <http://www.planalto. 
gov.br/ccivil_03/leis/L8078.htm>. Acesso em: 23 jul. 2018.

Brasil. Lei no 9.433, de 8 de janeiro, de 1997. Institui a Política Nacional de Recursos Hídricos, cria o Sistema Nacional de Gerenciamento de Recursos Hídricos, regulamenta o inciso XIX do art. 21 da Constituição Federal, e altera o art. $1^{\circ}$ da Lei no 8.001, de 13 de março de 1990, que modificou a Lei no 7.990 , de 28 de dezembro de 1989. Disponível em: <http://www.planalto.gov.br/ccivil_03/Leis/ L9433.htm>. Acesso em: 23 jul. 2018.

Brasil. Lei no 12.651, de 25 de maio de 2012. Dispõe sobre a proteção da vegetação nativa; altera as Leis $\mathrm{n}^{\text {os }} 6.938$, de 31 de agosto de 1981, 9.393, de 19 de dezembro de 1996, e 11.428, de 22 de dezembro de 2006; revoga as Leis nos 4.771 , de 15 de setembro de 1965, e 7.754, de 14 de abril de 1989, e a Medida Provisória no 2.166-67, de 24 de agosto de 2001; e dá outras providências. Disponível em: <http://www.planalto. gov.br/cciviL_03/_Ato2011-2014/2012/Lei/ L12651compilado.htm>. Acesso em: 23 jul. 2018.

Brasil. Supremo Tribunal Federal. Ação Direta de Inconstitucionalidade. ADIN no 3.540. Relator: Celso de Mello, Brasília, 2006. Disponível em: <http://www.stf.jus.br/ portal/processo/verProcessoAndamento.asp ?numero $=3540 \&$ classe $=$ ADI $\% 20 \&$ origem $=$ AP \&tipoJulgamento $=\mathrm{M} \&$ recurso $=0>$. Acesso em: 23 jul. 2018.

Dutra, S.C. A tutela ambiental no ordenamento jurídico brasileiro. Revista Jus Navigandi, v. 15, n, 2675, 2010. Disponível em: <http://jus.com.br/artigos/17711>. Acesso em: 25 jul. 2018.

Fiorillo, C. A. P. Curso de Direito Ambiental Brasileiro. 9 ed. São Paulo: Saraiva, 2008.

Giehl, G. O Direito Ambiental e a importância da água. Revista Âmbito Jurídico, v. 9, n. 36, 2007. Disponível em: <http://www.ambito juridico.com.br/site/index.php?n_link=revist a_artigos_leitura\&artigo_id=1635>. Acesso em: 25 dez. 2017.

Grazinela, M. L. M. Direito Ambiental. 3. ed. rev. atual. São Paulo: Atlas, 2014.

Lanfredi, G. F. Busca de rumos para a efetividade do Direito Ambiental. In: Lanfredi, G. F. Novos rumos do Direito Ambiental: nas áreas civil e penal. Campinas: Millennium, 2006. p. 14-15.
Le Prestre, P. Ecopolítica internacional. 2. ed. São Paulo: SENAC, 2005.

Malthus, T. Ensaio sobre o princípio da população como afecta o futuro progresso da humanidade com notas sobre as especulações de Mr. Godwin, M. Condorcet e outros escritores. Lisboa: EuropaAmérica, s.d. [1798]. (Livros de bolso, Ib 301).

Medeiros, M.S. Breve introdução ao Direito Ambiental e seus princípios jurídicos. Revista Jus Navigandi, v. 21, n. 4736, 2014. Disponível em: <https://jus.com.br/ artigos/34759>. Acesso em: 24 jul. 2018.

Nicolini, L. B.; Falcão, E. B. M.; Faria, F. S. Origem da vida: como licenciados em Ciências Biológicas lidam com este tema? Ciência \& Educação, v. 16, n. 2, p. 355-367, $2010 . \quad$ https://doi.org/10.1590/S151673132010000200006

Papa Francisco. Carta Encíclica 'Laudato Si' do Santo Padre Francisco sobre o cuidado da casa comum. Vaticano: Santa Sé, 2015. Disponível em: <http://w2.vatican.va/ content/francesco/pt/encyclicals/document s/papa-francesco_20150524_enciclicalaudato-si.html>. Acesso em: 23 jul. 2018.

Passos, P. N. C. A Conferência de Estocolmo como ponto de partida para a proteção internacional do meio ambiente. Revista Direitos Fundamentais \& Democracia, v. 6, 2009. Disponível em: <http://revista eletronicardfd.unibrasil.com.br/index.php/r dfd/article/viewFile/18/17>. Acesso em: 25 jul. 2018.

Peres, R. B.; Silva, R. S. Análise das relações entre o Plano de Bacia Hidrográfica TietêJacaré e os Planos Diretores Municipais de Araraquara, Bauru e São Carlos, SP: avanços e desafios visando à integração de instrumentos de gestão. Sociedade \& Natureza, v. 25, n. 2, p. 349-362, 2013. https://doi.org/10.1590/S1982-45132013 000200011

Rangel, T. L. V. 0 acesso à água potável alçado ao status de Direito Humano Fundamental: breve explicitação ao tema. Revista Jus Navigandi, v. 19, n. 3854, 2014. Disponível em: <http://jus.com.br/artigos/26428>. Acesso em: 25 jul. 2018.

Sampathkumar, K.; Arjunan, T. V.; Pitchandi, P.; Senthilkumar, P. Active solar distillation: A detailed review. Renewable and Sustainable Energy Reviews, v. 14, n. 6, 
p. 1503-1526, 2010. https://doi.org/ 10.1016/j.rser.2010.01.023

Silva, M. J.; Valente, A.; Costa, C. Origem da vida: as condições primordiais. Vila Real: Escola Secundária /3 Morgado de Mateus, 2011. Disponível em: <http://www.ciencia viva.pt/img/upload/Astrobiologia_Esc_Sec_M orgado_Mateus_origem\%20da\%20vida.pdf $>$. Acesso em: 23 jul. 2018.

Sirvinkas, L.P. Manual de Direito Ambiental. 10. ed. São Paulo: Saraiva, 2012.

Siqueira, L. C. Política ambiental para quem? Ambiente \& Sociedade, v. 11, n. 2, p. 425437, 2008. https://doi.org/10.1590/S1414753X2008000200014

Souza, M. N. O direito fundamental à água potável. Revista Âmbito Jurídico, v. 14, n. 92, 2011. Disponível em: <http://www.ambitojuridico.com.br/site/in dex.php?n_link=revista_artigos_leitura\&artig o_id=10330 >. Acesso em: 01 ago. 2018.

Vieira, Z. M. C. L.; Ribeiro, M. M. R. Mudando o paradigma: a gestão de recursos hídricos no Brasil. In: Paz, R. J.; Luna, R. G.; Farias, T. (Orgs.). Gestão ambiental: o caminho para a sustentabilidade. João Pessoa: Ed. Universitária/UFPB, 2010. p. 59-84.

Wolkmer, M. F. S.; Pimmel, N. F. Política Nacional de Recursos Hídricos: governança da água e cidadania ambiental. Sequência, n. 67 , p. 165-198, 2013. https://doi.org/ 10.5007/2177-7055.2013v34n67p165 